\title{
Healthcare Waste Management Practices in Jalingo: A Reflection of the State of Healthcare System in Taraba State, Nigeria
}

\author{
Article by Paul Rambe Yunana \\ Ph.D. in Public Health, Texila American University, Nigeria \\ E-mail: pyunana@gmail.com
}

\begin{abstract}
A strong healthcare system is known by efficiency in service delivery through its individual components. The poor quality service delivery by any of these components is a reflection of the degree of its weakness. To achieve a strong health system that will provide efficient and effective health services, there must be a deliberate effort towards strengthening the system and continuous improvement of quality of services in each component at all levels. Previous studies in some hospitals in central and southern parts of Nigeria revealed poor knowledge and waste management practices. The study was undertaken to assess healthcare waste handling practices in some selected hospitals in Jalingo Taraba state and appraise how the poor health system is reflected in this area of service delivery. The assessment was conducted by extensive review of literature on Nigerian health system as relates to healthcare waste management practices; and by direct observation of waste handling practices in those hospitals, compared to standard practices of healthcare waste management. The results revealed that the healthcare waste management in those health facilities is far below WHO standards. This is attributable to the weak and poor healthcare system in the state and the country. Having an implementable hospital waste management plan, training healthcare workers of all cadres on proper waste management and regular supervision by health facility management were recommended as measures to improve healthcare waste management in the state, which is also a way of health system strengthening through this aspect of service delivery.
\end{abstract}

Keywords: Healthcare, Inefficiency, Waste Management, Quality Service, System Strengthening.

\section{Introduction}

A health system or healthcare system refers to the organization of people, institutions, material and human resources put together to provide health services to meet the health needs of a specific population (Abdulraheem, Olapipo, Amodu, 2012; World Bank, 2007). A good health system according WHO $(2007,2014)$ delivers quality services to all people, when and where they need them. It requires a robust financing mechanism (Timothy, Irinoye, Yunusa, Dalhatu, Ahmed, Suberu, 2014), a well-trained and adequately motivated workforce; reliable information for policy making; with facilities and logistic system that are well maintained in order to deliver quality health services (WHO, 2015). Many past studies on Nigerian's healthcare system described it as weak and poor, faced with many problems (Ademiluyi et.al. 2009; NSHDP, 2009-2015; IOM, 2014). These challenges and problems have over the years stalled its development and growth. Olakunle (2012) noted that Nigeria Health system, Taraba state inclusive, is far from providing efficient health services due to many problems bedeviling it. The scanty literatures on Taraba state healthcare system also revealed a more pathetic healthcare service delivery situation (Who 2015). The major challenges and problems can be attributed to poor leadership and coordination, inadequate human resources for health, inadequate supplies of medical products and technologies, poor health information management (weak Monitoring and evaluation system for health) and weak health insurance system (WHO, 2009, 2012). 
This weak system is reflected in all components of health services, as seen in the healthcare waste management and disposal in the hospitals in the state. The minimum standard approaches required for handling healthcare wastes are: a written plan for waste treatment with clearly defined roles and responsibilities, knowledge and self-awareness about healthcare waste, segregation and safe collection, temporary storage and transportation, choice of appropriate treatment option before final disposal and sustainable ways of safe treatment plan in line with existing policies (WHO, 2005; 2014, PATH, 2009). The Plan outlines how waste will be treated and how many times in a specified period with clearly defined responsibilities of healthcare staff that will handle waste treatment. The plan must be in line with the health facility and existing national policies on waste treatment.

Knowledge and self-awareness of healthcare waste risks: In addition to universal safety precaution observed in health care facilities, all staff must know the risk involved in handling all categories of hospital waste and must have adequate knowledge of safe ways to handle waste. This is enhanced by training and regular continuous medical education.

Waste segregation: Waste in health facilities is handled by segregating it according to WHO guidelines and classification of healthcare waste. It is separated in to: infectious sharps, non-sharp infectious waste, and non-infectious wastes. This segregation is done at point of waste generation where they are collected in dedicated color-coded containers, while sharps are collected in puncture proof containers e.g. biosafety boxes with cover and biohazard symbol (WHO, 2012).

Waste treatment options: Depending on the category of waste, the option of treatment is chosen. Some waste are incinerated before their by product is finally disposed in landfills. Some waste may not be good for incineration because of their impact on the environment, as such they are buried in a deep pit as means of final disposal (WHO, 2014, 2015; Abah \& Ohimain, 2011).

It is a matter of concern to state that observations made by the authors whose works were reviewed on the status of Nigerian healthcare system, particularly healthcare waste management revealed poor waste management practices across all level of healthcare delivery system. This is undoubtedly attributable to the weak health system. This regrettable situation exposes healthcare workers, the patients including patient relations and the immediate environment of the health facilities, where those wastes are generated, to risk of infection and other hazardous effect of such waste. Most of the interventions geared towards strengthening Nigerian's health system have been largely donor funded (Uneke, Ezeoha, Ndukwe, Oyibo \& Onwe, 2010) and do not most of the times focus on waste management but on other areas, such as infrastructural upgrade, improving maternal and child health care, laboratory services and so forth (Uneke et al. 2010).

Previous studies in some hospitals in central and southern parts of Nigeria revealed poor waste management practices (Babalola, 2008; Cooker, 2009; Awodele, Adewoye \& Oparah, 2016; Toyobo, Baba, Oyeniyi, 2012), and scanty information on hospital waste management in Taraba State. The efforts and interventions launched by the government at different times in the past did not directly target proper waste management. Most of the interventions remained at the policy level and implementation of those policies were not actively pursued (Uneke et al. 2010). It is pertinent that the country's efforts at national and state levels have not given the needed attention to improving waste management in the healthcare system (Olakunle, 2012). It is in this light that this study was carried out, to appraise and present the extent of poor management of hospital waste, due to decay in the health system; and its attendant risks to policy makers and health care implementers for possible action.

The framework used to guide this study is the WHO framework of Health system strengthening. It looks at the health system issues according to their individual building blocks. Recommendation for improving the system is best approached through these individual elements.

The WHO Health Systems Framework 
System building blocks

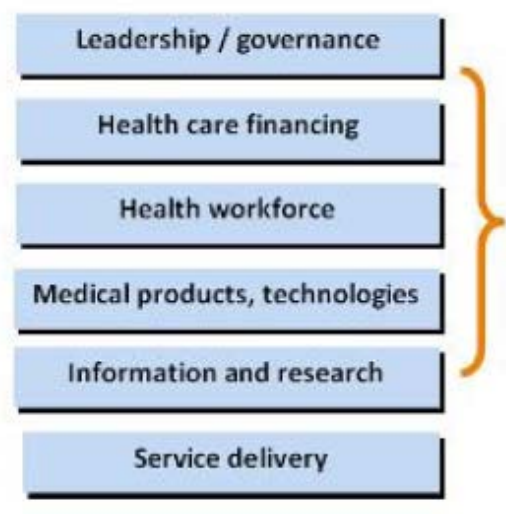

Goals/outcomes

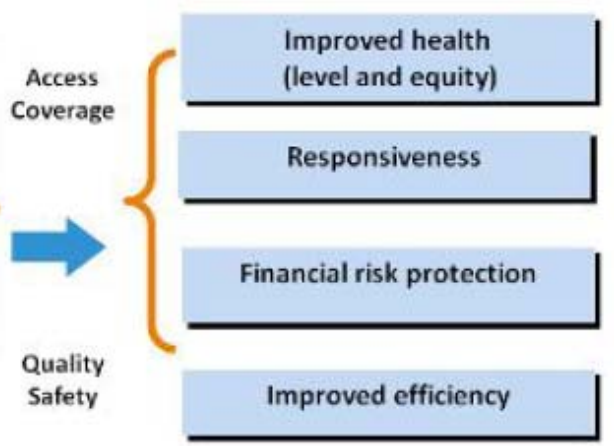

Source: WHO Health Services

Department.http://www.wpro.who.int/health_services/health_systems_framework/en/

The aim of the study was to present the outcome of weak healthcare system in Nigeria, hitherto described by many researchers as failed health system as reflected in poor hospital waste management in Taraba state and recommend ways for improvement.

The specific objectives of the study were:

1. Review relevant literatures to get grasp of the extend of the problems of Nigeria Healthcare system

2. Conduct a visit to selected health facilities to observe and appraise their waste management and disposal practices and relate them to the current state of the healthcare system of the state.

3. Recommend ways for strengthening healthcare systems through improved waste handling and disposal practices in the Taraba State and Nigeria at large.

\section{Methods}

The study was carried in Jalingo the capital of Taraba State. It is located in the north eastern part of Nigeria. The study was conducted between September and October, 2015. It adopted a cross sectional descriptive study design. The method employed was an extensive review of relevant literature on Nigeria's health system and healthcare /hospital waste management practices supplemented by physical observation of how hospital waste are managed and disposed in seven selected hospitals in Jalingo town. The content and ideas were synthesized and related to the practices of waste management observed in those hospitals. This was used to write a research supported article with recommendations to policy makers and healthcare services implementers to adapt in order to improve the healthcare system and thus healthcare waste management and disposal system.

Seven health facilities comprising of a Federal Medical Centre, a State specialist Hospital, 3 primary health healthcare centers, a faith based clinic and one private health facility all located in Jalingo, the capital town of Taraba state were purposively selected for their being popular facilities patronized by patients for observation on waste management practices.

For ethical consideration, permission was sought from the management of the health facilities visited in order to obtain a documented consent for the researcher to interact with the staff handling hospital waste.

Results

Summary of factors responsible for weak healthcare system in Nigeria Health system elements Weaknesses (building blocks)

Leadership /Governance Poor leadership and coordination: This is attributed to frequent changes in leadership, corruption and non-implementation of policies, guidelines and protocols. 
Texila International Journal of Public Health

Volume 4, Issue 4, Dec 2016

Financing

Inadequate and inappropriate financial allocation to the health sector at the three tiers of government- national, state and local government. Where there are meagre funds allocated to health sector, they are usually hardly released for the purpose.

Health workforce

Inadequate human resources for health, poorly motivated workforce, and frequent strike action by workers affect healthcare services delivery.

Information and research Poor record keeping, hospital records handled by untrained personnel. Improper storage of service data. Poor data management by health facilities.

Medical products, technologies

Obsolete equipment, poor maintenance practices for broken down equipment, frequent stock outs of essential medicines and commodities. Poor logistic management system.

Service delivery $\quad$ Decayed infrastructures, poor provision of quality health services. Poor attitude to work by health care workers. Overcrowded hospital wards. None adherence to professional and medical ethics.

\section{Summary of common waste management practices}

1. Most staff handling waste has not been trained on waste management. One Health facility outsourced it waste management to a company whose staff are also not trained.

2. Only two health facility practiced waste segregation, using coded bin most without bin lining. The rest of the facilities mixed their waste in one common bin before they are taken to the dump site.

3. Only two facility had incinerator for waste management. Two PHCs burn their waste in an open place within the hospital premises.

4. All the facilities have sites for dumping mixed waste within the hospital premises before they are conveyed to Landfills untreated.

\section{Discussions}

The effect of poor or weak health care system to the various units of healthcare service delivery are many. This study illustrates one of them. It shows how this affects healthcare waste management practices. Even at facility level, leadership is observed to be a problem. Weak leadership results in poor coordination and management of resources at all levels of health service delivery. At health facility level this does not only result in poor management of resources but also in poor supportive supervision of subordinate staff and in inadequate mentoring of staff by the management team or supervisors. Staffare left unsupervised and so they do what they feel right even when not in line with standard practices and waste management policy. Some of them do not have the adequate knowledge of proper waste handling and disposal. It is the responsibility of the leadership to provide needed training for all staff, so that they can perform their jobs effectively.

Finance: Funding has been identified as one of the major problems of the health sector. Inadequate and inappropriate financing affects every area of service delivery. From procurement of equipment, commodities and training to the payment of salary of staff rests on available funding for the health facility (Onisanwa, 2013; Timothy et.al. 2014; Uneke et.al, 2010). During interaction with the staff in the facilities visited, the common reason given for poor waste management by most of the staff asked, was poor financing. When the funding is adequate and prudently utilized, the management will procure materials for waste management while more staff will be employed in the facility and distributed fairly to all units. There will thus be adequate staffing for handling and disposing waste in line with the 
waste management plan of the health facility. There is therefore need for prioritizing the funding of health facilities by their owners if they must deliver the quality services expected of them. It is a common practice in Nigeria for government and Health facility owners to make annual budgets for health services but later fail in release of the funds appropriated for the services (Welcome, 2011). Appropriate allocation of funds should be followed by timely release to achieve the purpose for which the funds were budgeted.

Health workforce: The dearth of human resources for health is not only in Nigeria. It is reported almost in every developing country (Olaleye, 2014; Itam \& Adindu, 2012). The most important thing is what each country does to address them. The inadequate human resources coupled with lack of adequate training for the available staff is also responsible for the failure of many staff to perform their assigned duties rightly. In some of the facilities visited, the staff saddled with responsibility for waste management were grossly inadequate in number and training, while many skilled healthcare workers at various units do not see waste handling as part of their duty but for the very few persons designated for it.

Medical products/technologies. In an ideal healthcare facility, essential medical equipment and commodities are made available for efficient service delivery. In a country with weak health system most of these equipment are either obsolete or unavailable. Infection prevention and control (IPAC) consumables such as bio safety boxes, colour-coded bins and bin linings, gloves, face masks, boots and the like are infrequently supplied or not supplied at all. None segregation of waste in four out of seven health facilities visited were mainly due to lack of supply of the coded bins and bin linings in those facilities. Incinerators were not also sighted in four hospitals some of which are the major public health facilities in the state.

Information and research. A good practice of collecting, collating and managing hospital service data serves as the most important source (s) of information for planning, research and, decision making (IOM, 2014, Welcome, 2011). In a weak healthcare system, quality data and its efficient management for use are not a regular practice. If service data are not regularly analysed and used for planning, the hospital will not know the number of patients it serves at any point in time. It will be difficult to plan for how to effectively manage the waste that will be generated during services provided to patients at various units in the hospital. If the hospital does not know the average number of surgical operations it carries out every week, it may not plan well for how to appropriately handle and properly dispose the waste generated at the operating theatre. Hence the need for capturing service data and using it appropriately. Service data can also be secondary sources of information for research.

Service delivery: For efficient healthcare service delivery, the other five elements of health system strengthening (WHO, 2014) must be in place. Good service delivery depends on wellmotivated work force, good coordination by the leadership, appropriate funding which translates to adequate and equitable provision of material resources and efficient information management system (IOM, Adindu, \& Asuquo, 2013). This study revealed poor hospital waste handling and disposal practices in Jalingo. It is an example of poor service delivery attributed to issues that are directly related to a weak health care delivery system.

In the seven Hospitals visited, only 2 had written waste treatment plan. The two are both public health facilities, one owned by the federal government while the other by the state government. A good practice observed in all the hospitals was the use of bio safety boxes for sharps (majorly needles). These biosafety boxes are usually dumped alongside other waste at the dump sites. Segregation of waste using color-coded waste bins was observed in only one facility, while others do not pay attention to separating waste according to standard practices. Further interaction with staff who manage the waste, revealed inadequate knowledge on waste segregation. The lack of incinerator in most of the facilities visited including the two major public facilities suggest that the health facilities prefer conveying waste without treating them to the landfills. Some of them burn their waste in the open within the hospital premises. In the two facilities that had incinerator, wastes were also sighted at some hidden corners within the premises of the hospitals. In all the health facilities visited, waste were sighted within the premises either in a big ditch or open space or a container where they are usually carried and 
conveyed to the landfills. The danger to human life by this is also increasing. The waste handling and disposal in health facilities within Jalingo is similar to the one reported by earlier studies in Nigeria.

Poor waste handling poses great danger to healthcare workers, patients, the environment and immediate community where the hospital is located. When rain falls, it washes some of the wastes to the rivers and streams thereby polluting and contaminating water sources. Those that are burn within the hospital premises pollute the air with dangerous fumes. The danger of these practices is transmission of infection and pollution of the environment. This is of public health importance and attention must be given to it..

\section{Recommendations}

In order to improve the waste management and disposal system in Taraba state and in Nigeria, attention must be paid to the entire health system as a long term measure, while the short term measures should be the deliberate actions taken to improve the waste management practices so as to prevent its danger to the health workers, patients and the community.

\section{On health system}

1. Strong leadership and governance is required to strengthen coordination of healthcare services at all levels in the country. Relevant policy documents and guidelines exits, but they are not being implemented. Government at all levels (federal, state and local government) should enforce the implementation of the policy on Health and the National Health bill recently signed by the President of Nigeria.

2. Governments and other health facility owners should increase financial allocation for health sector and health facilities and back it with timely release of such funds in order to meet financial needs of the sector.

3. Public health intervention programs focusing on health system strengthening and continuous quality improvement at health facility should be pursued by Government and supported by donor agencies to strengthened health system in Nigeria at all levels of healthcare delivery.

4. More skilled health workers should be engaged to fill in the large human resource gap in the sector. Both public and private health institutions should be encouraged to implement the task shifting policy to address human resources for health issues in their respective intuitions. There should be training and re-training of health workers by its employers and strict enforcement of ethical and professional practices.

5. Government should make the national health insurance scheme viable by reorganizing it, and reposition it to provide equitable and affordable health services to all citizens in the country.

\section{On healthcare waste management}

1. All health facilities and their management should be sensitized to understand the risk in poor handling of hospital waste and measures to take in order to improve the this aspect. This is a primary responsibility of department of public health at the federal ministry of health.

2. Government and stakeholders in health should ensure all health facilities have clear written down implementable plan for waste management and should enforce the implementation of such plans.

3. All health facility staff should be trained on waste management and such should be included in the facility regular continuous medical education. Those whose schedule is handling waste should be provided with the appropriate protective clothing to minimize transmission of infection during handling.

4. Hospital management should always make available in the hospital infection prevention and control materials like the color coded waste bins, safety boxes, built 
incinerator and form a committee for waste management that will ensure adherence to standard practices.

5. Health facility management should ensure regular supportive supervision of their staff during work especially those responsible for waste handling and disposal.

6. The State Government should standardized the minimum requirements for hospital waste management and include it in the registration criteria for private hospitals.

7. Periodic studies should be conducted on waste management practices to assess improvement, identify and fill in the gaps for continuous quality improvement.

\section{Conclusion}

There is no doubt in the saying that Nigeria health system is weak and grappling with many problems. These problems have affected many if not all areas of health services delivery in the country including waste management system in health care facilities. There is hope of reviving and strengthening the system such that, all services that were affected will gradually improve for the benefit of all citizens. These will translate to improvement in all areas including the healthcare waste management system. These can be achieved if bold steps are taken to immediately implement the recommendations actions put forth for the improvement of the healthcare and waste management systems. Periodic assessment and research in this sector will also help in monitoring the improvement in health system and waste management practices.

\section{Tables and figures}




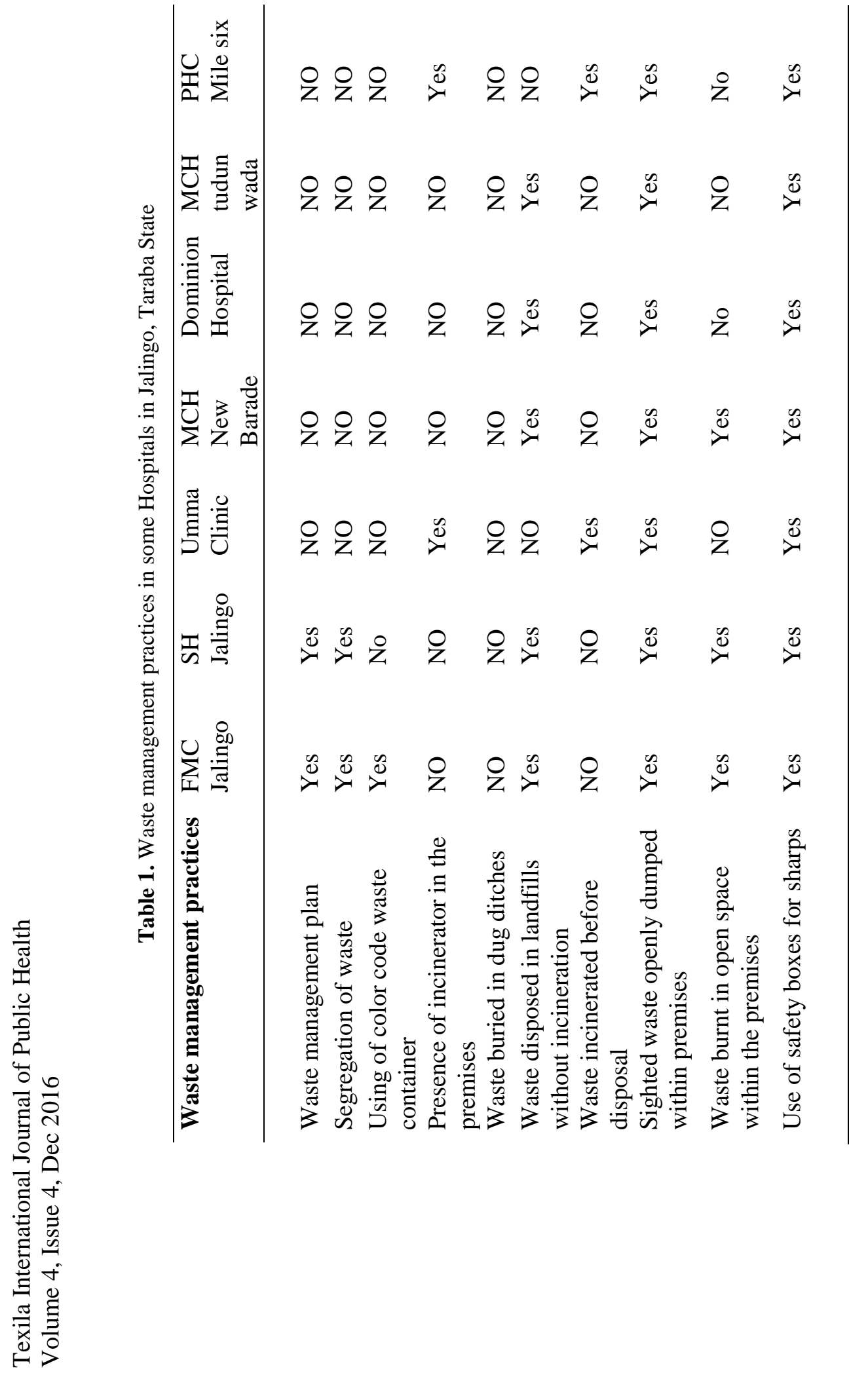


Table 2.

\begin{tabular}{lll}
\hline Waste management practices & $\begin{array}{l}\text { No of facilities } \\
\text { visited engaged in } \\
\text { the practice }\end{array}$ & $\begin{array}{l}\text { \% of facilities } \\
\text { visited }\end{array}$ \\
\hline
\end{tabular}

Waste management plan

Segregation of waste

2

28.6

Using of color code waste container

14.3

Presence of incinerator in the premises

1

28.6

Waste buried in dug ditches

Waste disposed in landfills without

2

0 incineration

Waste incinerated before disposal

0

Sighted waste openly dumped within

14.3

premises

Waste burnt in open space within the premises

Use of safety boxes for sharps

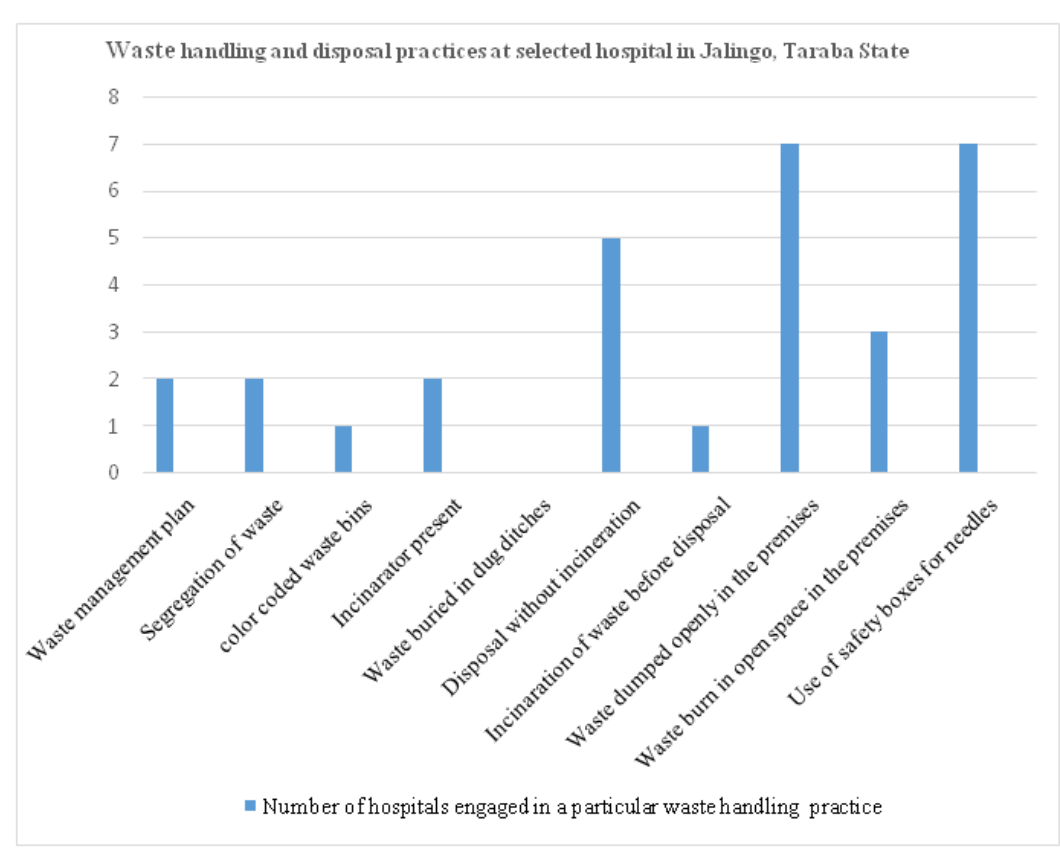

Fig.1.1

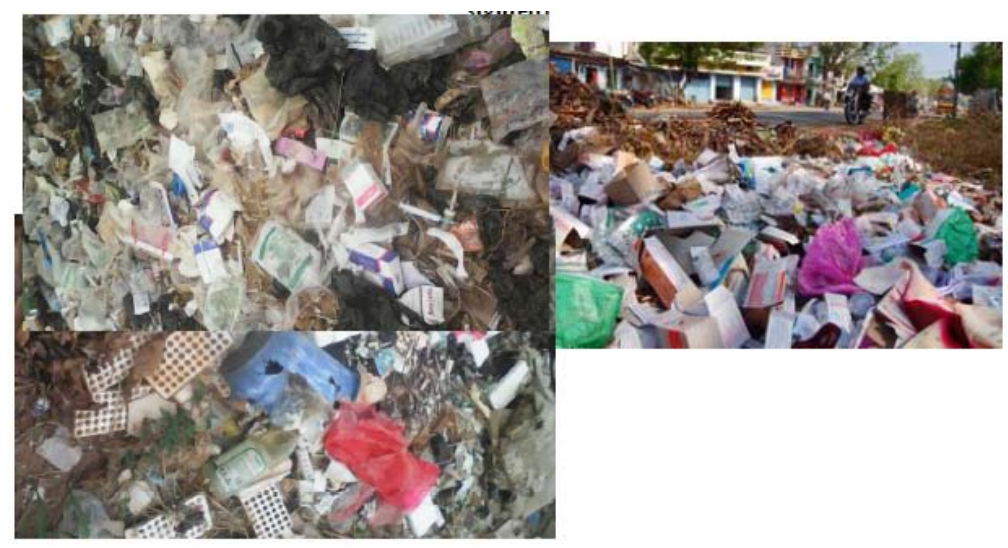


Texila International Journal of Public Health

Volume 4, Issue 4, Dec 2016

Fig 1.2 Pictorials (Pictures of improper hospital waste dumping sighted)

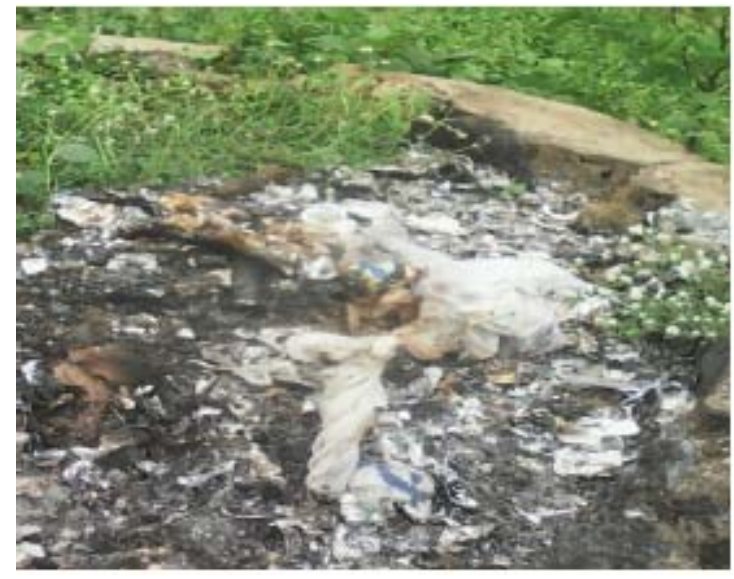

Waste at dump sites before conveying to landfills

Waste burn in open space within facility premises

\section{References}

[1] Abah SO, Ohimain EI (2010). Assessment of Dumpsite Rehabilitation Potential using the Integrated Risk Based Approach: A case study. Online at http://www.academicjournals.org/jphe. Accessed October 9, 2015.

[2] Abah, S. O., Ohimain, E. I (2011). Healthcare waste management in Nigeria: A case study. Journal of Public Health and Epidemiology Vol. 3(3), pp. 99-110, March 2011. Available online at http://www.academicjournals.org/jphe ISSN 2141-2316 (C2011 Academic Journals. Accessed October 19, 2015.

[3] Abdulraheem I. S., Olapipo A. R. Amodu M. O. (2012). Primary health care services in Nigeria: Critical issues and strategies for enhancing the use by the rural communities. Journal of Public Health \& Epidemiology Vol. 4(1), pp. 5-13, January 2012. Available online at http://www.academicjournals.org/JPHE DOI: 10.5897/JPHE11.133 ISSN 2141-2316.

[4] Adegbita M. A, Nwafor S. O, Afon A, Abegunde A. A, Bamise C. T (2010). Assessment of dental waste management in a Nigerian tertiary hospital. Waste. manag. Res., 28: 769-777.

[5] Ademiluyi, I.A., Aluko-Arowolo, S.O. (2009) Infrastructural distribution of healthcare services in Nigeria: An overview, Paper review. Journal of Geography and regional planning vol. 2(5) pp. 104110, May 2009. Available online http://www.academicjournals.org/article/article1379432402_Ademiluyi\%20and\%20AlukoArowolo.pdf. Accessed October 19, 2015.

[6] Adindu, A \& Asuquo, A. (2013). Training human resources for the $21^{\text {st }}$ Century Nigerian Health Sector. Global Journal of Human Resource Management Vol. 1, Issue 3, pp.1-11, September 2013 Published By European Centre for Research Training and Development UK. http://www.eajournals.org/wp-content/uploads/

[7] Awodele, O., Adewoye, A. A., \& Oparah, A. C. (2016). Assessment of medical waste management in seven hospitals in Lagos, Nigeria. BMC Public Health, 16, 269. http://doi.org/10.1186/s12889-016-2916-1

[8] Babatola, J.O (2008). A Study of Hospital Waste Generation and. Management Practice in Akure, Nigeria. www.ajol.info/index.php/afrrev/article/viewFile/41074/8499

[9] Coker (2009). Medical waste management in Ibadan, Nigeria: Obstacles and Prospects. February 2009. Waste Manag., 29(2): 804- 811.

[10] International Organization for Migration - IOM (2014). Needs Assessment of the Nigerian Health Sector. Available at https://nigeria.iom.int/sites/default/files/newsletter/

[11] Itam, H. I and Adindu, A (2012). Health Security in Africa and Quality of Health Services. Developing Countries Studies, vol.2, 11, 43 -50. 
[12] National strategic health development plan (NSHDP) 2009-2015

http://www.internationalhealthpartnership.net/fileadmin/uploads/ihp/Documents/Country_Pages/Nigeri a/Nigeria\%20National\%20Strategic\%20Health\%20Development\%20Plan\%20Framework\%2020092015.pdf

[13] Olakunle, B. O (2012). Public Healthcare financing in Nigeria: Which way forward? An article review. Annals of Nigerian Medicine / Jan-Jun 2012 / Vol 6 | Issue 1. Downloaded free from http://www.anmjournal.com, October 18, 2015, IP: 105.112.20.120

[14] Olaleye, F.(2014). Human resource management in health care delivery systems: Challenges, trends and strategies. Healthcare and Leadership series, Pharma news. Available at http://www.pharmanewsonline.com/human-resource-management

[15] Onisanwa, I.D. (2013). The Impact of Health on Economic Growth in Nigeria. Journal of Economics and Sustainable Development www.iiste.org ISSN 2222-1700 (Paper) ISSN 2222-2855 (Online) Vol.5, $\quad$ No.19, $2014 . \quad$ Available at http://www.iiste.org/Journals/index.php/JEDS/article/viewFile/16114/16445

[16] PATH (2009). Achieving effective sharps waste management in GAVI host countries. A proposed approach with estimates of cost 2006 Available at http://www.Path.org/files/TS_ach_eff_swm.pdf.

[17] Timothy, G., Irinoye, O., Yunusa, U., Dalhatu A., Ahmed, S. Suberu, A. (2014). Balancing Demand, Quality and Efficiency in Nigerian Health care Delivery system. European Journal of Business and Management ISSN 2222-1905 (Paper) ISSN 2222-2839 (Online)

[18] Toyobo A.E., Baba A.O, Oyeniyi A.B. (2012) Appraisal of university teaching hospital medical waste management in Nigeria: Case Studies of University College Hospital (UCH) Ibadan and Obafemi Awolowo University Teaching Hospital (OAUTH) Ile-Ife, Nigeria. Vol.6, No.23, 2014. Retrieved October 18, 2015 from: www.iiste.org

[19] Uneke, C. J., Ezeoha, A. E., Ndukwe, C. D., Oyibo, P. G., \& Onwe, F. (2010). Development of Health Policy and Systems Research in Nigeria: Lessons for Developing Countries' Evidence-Based Health Policy Making Process and Practice. Healthcare Policy, 6(1), e109-e126. https:/www.ncbi.nlm.nih.gov/pmc/articles/PMC2929895/

[20] Welcome, M. O. (2011). The Nigerian health care system: Need for integrating adequate medical intelligence and surveillance systems. Journal of Pharmacy \& Bioallied Sciences, 3(4), 470-478. http://doi.org/10.4103/0975-7406.90100. Accessed October 19, 2015 from http://www.ncbi.nlm.nih.gov/pmc/articles/PMC3249694/

[21] WHO (1999). Safe management of wastes from health-care activities, edited by A. Prüss, E. Giroult and P. Rushbrook. Geneva, WHO, 1999, 228 pages. Available at: http://www.who.int/water_sanitation_health/Environmental_sanit/MHCWHanbook.htm

[22] WHO (2012). Ten facts on Universal health coverage. Features: fact files May 2012. Available at http://www.who.int/features/factfiles/universal_health_coverage/en/

[23] WHO (2014) Safe management of wastes from health-care activities / edited by Y. Chartier et al. - 2nd ed. http://www.healthcare-waste.org/fileadmin/user_upload/resources/Safe-Management-ofWastes-from-Health-Care-Activities-2.pd

[24] WHO (2015). Health systems: Tracking Universal health coverage. Accessed October 15, 205 from: http://www.who.int/healthsystems/en/

[25] WHO (2007). Towards better leadership and management in health. Report on International consultation on strengthening leadership and management in low income countries, February 2007. pp

2-13.http://www.who.int/management/working_paper_10_en_opt.pdf?ua=1

[26] WHO (2005). Management of Solid Health-Care Waste at Primary Health-Care Centres: A Decision-Making Guide. World Health Organization, Geneva, 2005, 57 pages. ISBN 9241592745. Available at: http://www.who.int/water_sanitation_health/medicalwaste/decisionmguide_rev_oct06.pdf Accessed October 20, 2015.

[27] World Bank (2007). Healthy Development: The World Bank Strategy for HNP Results Annex L-April 24, 2007. Available at.

http://siteresources.worldbank.org/HEALTHNUTRITIONANDPOPULATION/Resources/2816271154048816360/AnnexLHNPStrategyWhatisaHealthSystem/ 